\title{
Prevention of influenza in the general population: recommendation statement from the Canadian Task Force on Preventive Health Care
}

\author{
Joanne M. Langley, Marie E. Faughnan, and the Canadian Task Force on \\ Preventive Health Care
}

S See related article page 1213

\section{Recommendations}

- The Canadian Task Force on Preventive Health Care recommends influenza vaccination in healthy adults (grade A recommendation) and children (grade A recommendation).

- There is good evidence to support neuraminidase inhibitor prophylaxis against influenza in the household setting if it can be initiated within 36-48 hours of symptom onset in the index case (grade $\mathrm{A}$ recommendation).

Tnfluenza virus causes yearly $\perp$ epidemics of respiratory illness of varying severity worldwide in people of all ages, and it may be the most important cause of medically attended acute respiratory illness. ${ }^{1}$ In healthy adults illness is usually self-limited, with fever, cough, myalgia, headache and other symptoms abating at 3 to 6 days, although 3 to 4 work days may be lost and up to $34 \%$ of patients will visit a health care provider. ${ }^{2-4}$ The rates of complications, hospital admissions and death from influenza are high among adults over 65 years of age and those with cardiac or pulmonary disease or chronic medical conditions, and annual influenza immunization is recommended for these groups. Immunization is also recommended for caregivers and household contacts who can transmit influenza to people who are at high risk for complicated disease..$^{5-7}$

The goal of influenza immunization programs targeted at high-risk people is to avert serious consequences of infection, such as complications and death, rather than to prevent the annual winter epidemic of infection. Because influenza occurs yearly and because reinfections occur throughout the lifespan and affect up to $20 \%$ of the population each year, considerable attention has been directed to the prevention of infection in healthy people. The rationale for prevention in healthy adults has been to avoid economic loss associated with lost work days and health care provider visits, to decrease antibiotic use and to prevent complications.

Previously healthy young children are increasingly recognized as having hospital admission rates comparable to those of elderly people during influenza epidemics, ${ }^{8}$ and they are also known to shed the virus in higher quantities and for longer periods than do adults, which makes them efficient disease transmitters. ${ }^{9}$ Immunization of Japanese schoolchildren has been associated with a reduction in excess winter deaths in adults, and these deaths increased when the program was discontinued. ${ }^{10}$

\section{Manoeuvres}

- Immunization with injectable inactivated influenza vaccine or nasally administered live- attenuated influenza vaccine in healthy adults or children before each winter respiratory virus season

- Prophylactic administration of neuraminidase antiviral agents (oseltamavir or zanamavir) to household or close contacts within 36-48 hours of symptom onset of influenza in the index case

\section{Potential benefits}

- Prevention of influenza in the person receiving the vaccine or antiviral agent

- Decreased economic disruption from lost work days and health care provider visits

- Although it is plausible that prevention of influenza decreases the adverse consequences of infection, there is no direct evidence from randomized controlled trials that immunization of healthy adults and children decreases the risk of secondary complications from influenza (e.g., bacterial pneumonia), hospital admission rates in the winter season, secondary spread of influenza to people at high risk for complications (e.g., hospital admission because of respiratory disease, congestive heart failure and death) or antibiotic use for respiratory infection and secondary bacterial pneumonias

\section{Potential harms}

- Discomfort at the injection site for 24 to 48 hours after vaccination 
Practice

- Rhinorrhea and sore throat in recipients of nasally administered live-attenuated vaccine

- Nausea and vomiting in recipients of oseltamavir

\section{Recommendations by others}

The US Preventive Services Task Force continues to recommend annual influenza vaccination only of high-risk people and adults over 65 years old. ' The US Centers for Disease Control and Prevention recommends immunization of high-risk people and adults over 50 years old because of the increased incidence of high-risk conditions in that age group. That body recently extended its recommendations to include influenza vaccination of children aged 6-23 months and close contacts of infants aged 0-23 months. ${ }^{5}$ In Canada, the National Advisory Committee on Immunization recom- mends that any person who wishes to be protected against influenza be offered the vaccine, in addition to those in high-risk groups and their close contacts. ${ }^{11}$

Joanne Langley is Associate Professor in the Departments of Pediatrics and of Community Health and Epidemiology, Dalhousie University, Halifax, NS; Marie Faughnan is Assistant Professor in the Department of Medicine, Division of Respirology, St. Michael's Hospital and University of Toronto, Toronto, Ont.

\section{Competing interests: None declared.}

Contributors: Joanne Langley drafted the current article and made subsequent revisions. Both authors wrote the original systematic evidence-based review. The Canadian Task Force on Preventive Health Care critically reviewed the evidence and developed the recommendations according to its methodology and consensus development process.

The Canadian Task Force on Preventive Health Care is an independent panel funded through a partnership of the federal and provincial/territorial governments of Canada.

This statement is based on the technical report: "Prevention of influenza in the general population: systematic review and recommendations," by Joanne M. Langley

\section{Evidence and clinical summary}

- There is good evidence that influenza vaccination of healthy adults is moderately effective. In a systematic review by Langley and Faughnan (see page 1213) 18 trials involving more than 33000 healthy adults were identified as meeting the criteria for the study design of a randomized controlled trial (RCT), and the results of all but 3 showed protection against influenza in the subsequent season. Eleven of the trials were considered to be of "good" quality, and 7 were considered to be of "fair" quality because of study characteristics that may have biased outcome ascertainment. Reflecting the variable annual attack rate of influenza, the incidence of laboratory-confirmed influenza in the control groups varied from 1.3 to 20 per 100 control subjects. The relative risk reduction (RRR) associated with influenza immunization ranged from $0 \%$ to $91 \%$.

- Fifteen RCTs involving more than 45000 healthy children aged 6 months to 19 years were included in the systematic review, of which 9 trials were considered to contain "good" evidence and 6 "fair" evidence. Of the 15 trials, the results of 12 showed protection against clinical influenza, whether laboratory-confirmed influenza or influenzalike illness. The RRR afforded by either live-attenuated or inactivated vaccines varied from $0 \%$ to $93 \%$. Laboratory-confirmed influenza attack rates in these studies varied from 5.8 to 51 events per 100 control subjects. The highest efficacy rate $(93 \% ; 95 \% \mathrm{Cl}$ $88 \%-96 \%$ ) was reported among children 15 to 71 months old who received 1 or 2 doses of a live-attenuated, trivalent, intranasal influenzavirus vaccine. Immunization did not prevent noninfluenza-associated respiratory tract illness.

- There is good evidence to support a recommendation for neuraminidase inhibitor prophylaxis in household contacts within 36-48 hours of symptom onset of a household index case of influenza. All 6 RCTs in the systematic review were considered to be of "good" quality. Neuraminidase inhibitor prophylaxis is expensive and is likely to be prohibitively so in most settings, given drug costs of about $\$ 50$ per day. In order to use these agents appropriately, clinicians should be aware of influenza disease activity in the community or have access to rapid, accurate microbiologic diagnosis for influenza.

and Marie E. Faughnan, with the Canadian Task Force on Preventive Health Care. The full technical report is available from the task force at ctf@ctfphc.org.

\section{References}

1. Glezen WP, Keitel WA, Taber LH, Piedra PA, Clover RD, Couch RB. Age distribution of patients with medically-attended illnesses caused by sequential variants of influenza A/H1N1: comparison to age-specific infection rates, 1978-1989. Am 7 Epidemiol 1991;133(3):296-304.

2. Bridges CB, Thompson WW, Meltzer MI, Reeve GR, Talamonti WJ, Cox NJ, et al. Effectiveness and cost-benefit of influenza vaccination of healthy working adults: A randomized controlled trial. 7AMA 2000;284(13):1655-63.

3. Nichol KL, Lind A, Margolis KL, Murdoch $M$, McFadden R, Hauge M, et al. The effectiveness of vaccination against influenza in healthy, working adults. $N$ Engl 7 Med 1995;333(14):889-93.

4. Nichol KL, Mendelman PM, Mallon KP, Jackson LA, Gorse GJ, Belshe $\mathrm{RB}$, et al. Effectiveness of live, attenuated intranasal influenza virus vaccine in healthy, working adults: a randomized controlled trial. 7AMA 1999;282 (2):137-44.

5. Harper SA, Fukuda K, Uyeki TM, Cox NJ, Bridges CB; Centers for Disease Control and Prevention (CDC) Advisory Committee on Immunization Practices (ACIP). Prevention and control of influenza: recommendations of the Advisory Committee on Immunization Practices (ACIP) [published erratum in MMWR Recomm Rep 2004;53(32):743]. MMWR Recomm Rep 2004;53(RR-6):1-40.

6. National Advisory Committee on Immunization (NACI). An Advisory Committee Statement (ACS). Statement on recommended use of influenza vaccination for the 2002-2003 season. Can Commun Dis Rep 2003;28:1-32.

7. US Preventive Services Task Force. Adult immunizations. In: Guide to clinical preventive bealth services. 2nd ed. Baltimore: Williams and Wilkins; 1996. p. 791-814.

8. Neuzil KM, Mellen BG, Wright PF, Mitchel EF Jr, Griffin MR. The effect of influenza on hospitalizations, outpatient visits, and courses of antibiotics in children. $N$ Engl $7 \mathrm{Med}$ 2000;342(4):225-31.

9. Longini IM, Jr., Koopman JS, Monto AS, Fox JP. Estimating household and community transmission parameters for influenza. Am 7 Epidemiol 1982;115(5):736-51.

10. Reichert TA, Sugaya N, Fedson DS Glezen WP, Simonsen L, Tashiro M. The Japanese experience with vaccinating schoolchildren against influenza. N Engl 7 Med 2001;344(12):889-96.

11. National Advisory Committee on Immunization (NACI). Canadian immunization guide. 6th ed. Ottawa: Canadian Medical Association; 2002. p. 122-4.

Correspondence to: Canadian Task Force on Preventive Health Care, 117-100 Collip Circle, London ON N6G 4X8; fax 519 858-5112; ctf@ctfphc.org 
Members of the Canadian Task Force on Preventive Health Care

Chair: Dr. John W. Feightner, Professor, Department of Family

Medicine, The University of Western Ontario, London, Ont. Vice-

Chair: Dr. Harriet MacMillan, Associate Professor, Departments of

Psychiatry and Behavioural Neurosciences and of Pediatrics, Canadian

Centre for Studies of Children at Risk, McMaster University, Hamilton,

Ont. Members: Drs. Paul Bessette, Professeur titulaire, Département

d'obstétrique-gynécologie, Université de Sherbrooke, Sherbrooke,

Que.; R. Wayne Elford, Professor Emeritus, Department of Family

Medicine, University of Calgary, Calgary, Alta.; Denice S. Feig, Assistant

Professor, Departments of Medicine, of Obstetrics and Gynecology, and of Health Policy Management and Evaluation, University of Toronto,

Toronto, Ont.; Joanne M. Langley, Associate Professor, Departments of Pediatrics and of Community Health and Epidemiology, Dalhousie University, Halifax, NS; Valerie Palda, Assistant Professor, Department of General Internal Medicine, University of Toronto, Toronto, Ont.; Christopher Patterson, Professor, Division of Geriatric Medicine, Department of Medicine, McMaster University, Hamilton, Ont.; and Bruce A. Reeder, Professor, Department of Community Health and Epidemiology, University of Saskatchewan, Saskatoon, Sask. Resource people: Ruth Walton, Research Associate, and Jana Fear, Research Assistant, Canadian Task Force on Preventive Health Care, Department of Family Medicine, The University of Western Ontario, London, Ont. 